\title{
Clinical and biochemical characteristics of patients presenting with pituitary apoplexy
}

\author{
Ali Abbara1,*, Sophie Clarke1,*, Pei Chia Eng1', James Milburn², Devavrata Joshi², Alexander N Comninos ${ }^{1,2}$, \\ Rozana Ramli², Amrish Mehta², Brynmor Jones², Florian Wernig², Ramesh Nair², Nigel Mendoza², \\ Amir H Sam 1,2, Emma Hatfield², Karim Meeran ${ }^{1,2}$, Waljit S Dhillo ${ }^{1,2}$ and Niamh M Martin ${ }^{1,2}$ \\ ${ }^{1}$ Department of Investigative Medicine, Imperial College London, Hammersmith Hospital, London, UK \\ ${ }^{2}$ Imperial College Healthcare NHS Trust, London, UK
}

Correspondence should be addressed to N M Martin: n.martin@imperial.ac.uk

*(A Abbara and S Clarke contributed equally to this work)

\begin{abstract}
Purpose: To review the clinical and biochemical characteristics and clinical outcome of patients presenting with pituitary apoplexy to a tertiary centre.

Methods: We retrospectively reviewed the clinical features, predisposing factors, biochemistry and clinical outcome of patients presenting with pituitary apoplexy to Imperial College Healthcare NHS Trust between 1991 and 2015.

Results: We identified 64 patients with pituitary apoplexy (more complete clinical records were available in 52 patients). The median age at presentation was 46.7 years (IQR 31.5-57.0 years). Pituitary apoplexy was the first presentation of pituitary disease in $38 / 52$ of patients and predisposing factors were identified in $28 / 52$. Pituitary apoplexy predominantly occurred in patients with non-functioning pituitary adenomas (47/52). Headache was most commonly described as sudden onset, severe, lateralising to the frontal or temporal regions. Symptoms of meningeal irritation were reported in 7/18 and visual abnormalities in 22/35. A pre-treatment serum cortisol $<100 \mathrm{nmol} / \mathrm{L}$ was recorded in 12/31 of patients. All patients with visual disturbance had some resolution of their visual symptoms whether managed surgically (14/14) or conservatively (5/5), although pituitary endocrine function did not fully recover in any patient. Conclusions: In conclusion, these data describe the clinical features of pituitary apoplexy to aid the clinician in diagnosing this rare emergency presentation of pituitary disease. Prospective multicentre studies of the presentation of pituitary apoplexy are required to further characterise presentation and outcomes.
\end{abstract}

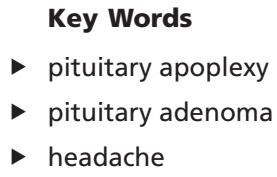

Endocrine Connections (2018) 7, 1058-1066

\section{Introduction}

Pituitary apoplexy is a clinical syndrome defined by an abrupt onset of headache, vomiting, visual impairment and/or reduced conscious level, due to rapid expansion of the contents of the sella turcica, caused by haemorrhage or infarction into the pituitary gland $(1,2,3)$. Visual abnormalities such as visual field deficits, impaired visual acuity or ocular palsies may arise due to compression of neuro-ophthalmic pathways in the pituitary fossa or extension into the cavernous sinus. Endocrinopathy in the form of partial or panhypopituitarism may also result from destruction of normal pituitary tissue or reduced blood supply to the pituitary gland $(1,2,3)$.

Pituitary apoplexy is frequently spontaneous, but predisposing factors can be identified in 10-40\% of cases $(2,4,5,6,7,8,9,10,11)$. These include hypertension, surgical procedures, head trauma, hypothalamic/pituitary

$$
\begin{array}{lr}
\text { https://ec.bioscientifica.com } & \text { ( ) } 2018 \text { The authors } \\
\text { https://doi.org/10.1530/EC-18-0255 } & \text { Published by Bioscientifica Ltd }
\end{array}
$$

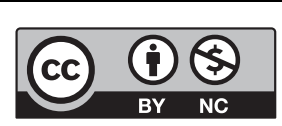

This work is licensed under a Creative Commons Attribution-NonCommercial 4.0 International License. 
stimulation tests, anticoagulation use and radiotherapy. Pituitary apoplexy may occur in either functioning or non-functioning pituitary tumours, but a higher predominance in non-functioning pituitary adenoma (NFPA) is recognised $(2,4,5,6,10)$. Patients with preexisting pituitary adenoma have a $2-12 \%$ chance of pituitary apoplexy; however, pituitary apoplexy is frequently the first presentation of pituitary disease $(1,4$, $6,11,12,13,14)$. Pituitary apoplexy is rare, and although described at all ages, it is most frequent in the fifth to sixth decades $(1,6,11,12,13,15)$.

As the clinical syndrome overlaps with other presentations such as meningitis and subarachnoid haemorrhage, recognition of pituitary apoplexy is challenging, which can cause delay in diagnosis and management. Clinical sequelae can vary, ranging from severe headache alone to acute deterioration in conscious level, visual disturbance or endocrine dysfunction. The initial management of pituitary apoplexy is supportive, including fluid resuscitation and correction of hormonal deficiencies. The potential for surgical management to improve recovery from neurological deficits remains a subject of conjecture in the absence of large randomised clinical trials $(6,15,16)$. Thus, variability in the clinical course and recovery make the optimal management of pituitary apoplexy challenging. Due to this uncertainty, access to a specialist multidisciplinary team's expertise, including input from neurosurgery, endocrinology and ophthalmology remains the prime course to impact positively the outcome of this condition (1).

As a rare condition, there are limited reports of cohorts of pituitary apoplexy in the literature. In this case series, we report our experience of managing patients with pituitary apoplexy presenting to a tertiary endocrine and neurosurgical centre. We reviewed clinical records of patients presenting with pituitary apoplexy to Imperial College Healthcare NHS Trust between 1991 and 2015 and describe presenting clinical features, predisposing factors and the clinical outcomes.

\section{Materials and methods}

We retrospectively reviewed clinical records of all patients who presented to Imperial College NHS Healthcare Trust with pituitary apoplexy during the period 1991 to 2015. We identified cases of pituitary apoplexy using electronic data search systems, clinic records and discharge summaries. Pituitary apoplexy was diagnosed by the attending physician/multidisciplinary pituitary team in patients with acute presentation of sudden severe headache with evidence of associated change in clinical condition for example visual field loss or ophthalmoplegia with CT/MRI evidence of haemorrhage/infarction. Clinically asymptomatic pituitary haemorrhages identified on imaging or histology were not included. In all cases, we reviewed the original medical records to retrieve information on details of clinical presentation, biochemical/endocrine abnormalities at presentation and imaging modalities used for diagnosis. The imaging modality used to make the initial diagnosis of pituitary apoplexy was recorded. The majority of patients subsequently had dedicated pituitary MRI imaging, which was used to assess imaging characteristics such as haemorrhage and size. Haemorrhage may complicate pituitary infarction and thus many patients have a mixture of both features. The proportion of pituitary MRI images with features consistent with predominantly haemorrhage and the proportion with features suggestive of infarction without overt haemorrhage were assessed. The clinical features of pituitary apoplexy assessed in this study relied upon documentation by the admitting physicians of signs and symptoms. Where clinical features were not clearly documented as either being present or absent, these were treated as missing data and recorded as not available (NA).

We compared clinical/biochemical characteristics of patients with pituitary apoplexy. Continuous variables were compared by unpaired $t$ test or by Mann-Whitney $U$ test depending on distribution of the data as appropriate, whereas categorical variables were compared by the Fisher's exact test or logistic regression. This audit of patients presenting with pituitary apoplexy was registered at Imperial College Healthcare NHS Trust audit office (AMC_012). Ethical review and consent were not required for this study.

\section{Results}

We identified 64 cases of pituitary apoplexy during the period between 1991 and 2015, of whom 34 were female (34/64) and 30 were male (30/64). In 52 patients for whom more complete clinical records were available, the median age of patients presenting with pituitary apoplexy was 46.7 years (IQR 31.5-57.0 years) (Table 1). Pituitary apoplexy was the first presentation of pituitary disease in 38 of 52 patients (Table 1). No putative predisposing factors were identified in 24 of 52 patients (Table 1). A preceding diagnosis of hypertension was present in one-third of patients $(17 / 52)$ and a quarter of women (7/27) were peripartum (Table 1$)$. In 3 of 52 patients, pituitary apoplexy was precipitated following administration of antiplatelet/anticoagulant therapy for acute coronary syndrome.

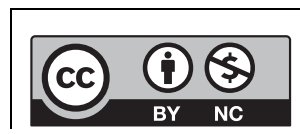

This work is licensed under a Creative Commons Attribution-NonCommercial 4.0 International License. 
Table 1 Demographics, predisposing factors and adenoma type in the patients who present with pituitary apoplexy.

\begin{tabular}{lc}
\hline & Number \\
\hline Demographics & $25 / 27$ \\
Number (males/female) & $49.5 / 42.8$ \\
Median age (male/female) (years) & $30.8-60.7 / 30.3-57.7$ \\
IQR (male/female) (years) & $1991-2015$ \\
Study period & $38 / 52$ \\
Number of patients with apoplexy as 1st presentation of pituitary disease & $14 / 52$ \\
Number of patients with previous diagnosis of pituitary disease & $17 / 52$ \\
Predisposing factors & $7 / 52$ \\
Previous diagnosis of hypertension & $4 / 52$ \\
Intrapartum/puerperal & $3 / 52$ \\
Diabetes mellitus & $2 / 52$ \\
Antiplatelet or anticoagulant & $2 / 52$ \\
Dopamine agonists & $24 / 52$ \\
Radiotherapy & $47 / 52$ \\
None & $5 / 52$ \\
Type of secretion of adenoma defined clinically or biochemically & \\
NF or GT & \\
PRL & \\
\hline
\end{tabular}

Number of patients with percentages are shown for categorical variables. Median and interquartile range are presented for continuous variables GT, gonadotroph adenoma; NF, non-functioning pituitary adenoma; PRL, prolactinoma.

\section{Presenting symptoms and signs}

Headache was documented in 40 of 43 patients diagnosed with apoplexy. Approximately half of the patients with headache also reported associated nausea/vomiting (22/43) (Table 2). Some patients presented with symptoms consistent with raised intracranial pressure; three patients reported improvement of the headache on sitting upright and one reported worsening of the headache on coughing (Table 3). Two patients presented with collapse and one patient presented with singultus (persistent hiccup). One patient was hypotensive (systolic BP <90 mmHg; serum cortisol of $118 \mathrm{nmol} / \mathrm{L}$ and serum sodium of $115 \mathrm{nmol} / \mathrm{L}$ on admission). However, 11/30 were hypertensive at presentation (systolic BP $>140 \mathrm{mmHg}$ ) (Table 2). Symptoms consistent with pituitary dysfunction

Table 2 Signs and symptoms in patients presenting with pituitary apoplexy.

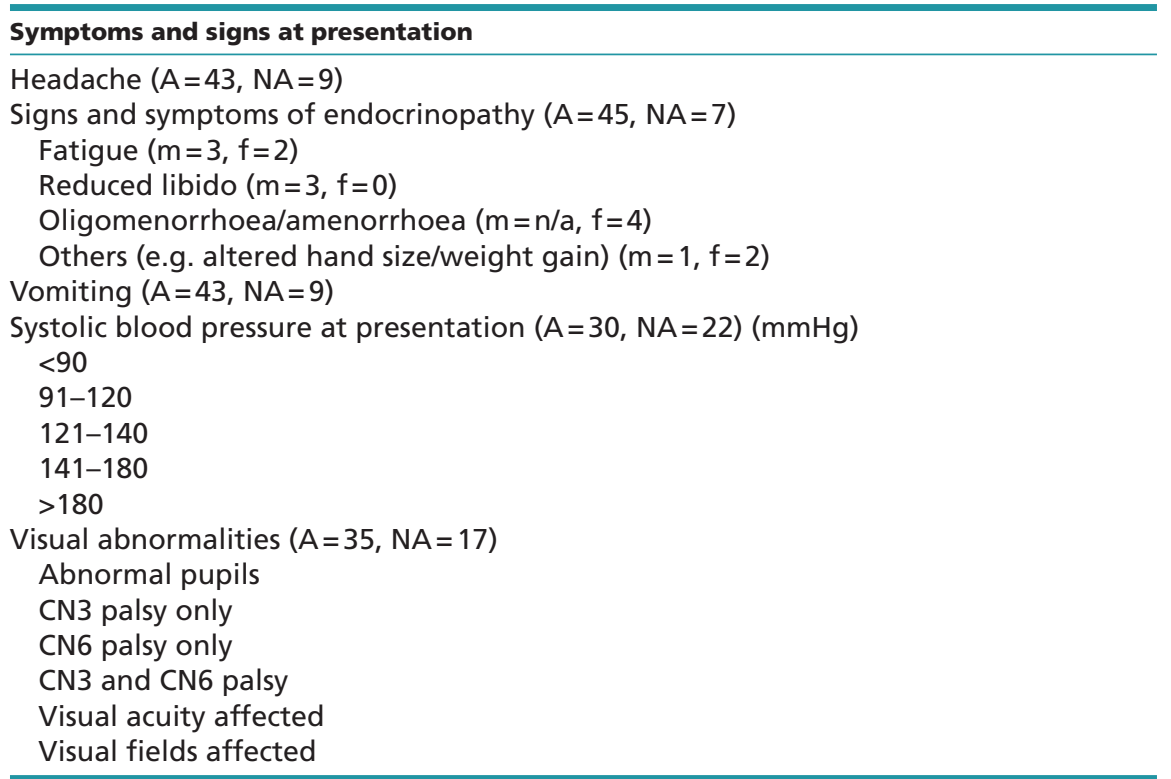

\begin{tabular}{c}
\hline Number/total in whom data available \\
\hline $40 / 43$ \\
$16 / 45$ \\
$5 / 45$ \\
$3 / 45$ \\
$4 / 25$ \\
$4 / 45$ \\
$22 / 43$ \\
$1 / 30$ \\
$11 / 30$ \\
$7 / 30$ \\
$10 / 30$ \\
$1 / 30$ \\
$22 / 35$ \\
$7 / 35$ \\
$12 / 35$ \\
$8 / 35$ \\
$3 / 35$ \\
$14 / 35$ \\
$13 / 35$ \\
\hline
\end{tabular}

Number of patients with variable and number for whom data available as denominator are presented. A, available data; CN3, cranial nerve 3; CN6, cranial nerve 6; f, female; m, male; NA, not available.

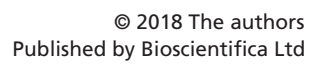

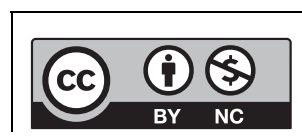

This work is licensed under a Creative Commons Attribution-NonCommercial 4.0 International License. 
preceding presentation were documented in $35.6 \%$, including fatigue (5/45), menstrual disturbance ( 4 of 25 women) and reduced libido (3/45) (Table 2).

In $17 / 23$, headache was of sudden onset, whilst in 6 of 23 patients, a more insidious onset was described (Table 3 ). The majority of patients $(15 / 19)$ reported that headache had been present for at least 1 day prior to presentation. Headache was described as unilateral in 11/17 and was purely frontal in $6 / 17$, temporal in $5 / 17$, occipital in $1 / 17$, apical in $1 / 17$ and a combination of regions in the remainder 4/17 (Table 3).

Visual abnormalities were reported in 22 of 35 patients. Impairment of visual acuity was the most common visual complaint (14/35) (Table 2). Ocular palsies were present in 20 of 35 patients, with involvement of oculomotor nerve palsy being most frequent (12/35). Anisocoria was observed in 7 of 35 patients (Table 2).

\section{Biochemical/endocrine results}

A serum cortisol $<100 \mathrm{nmol} / \mathrm{L}$ was present in $12 / 31$, gonadotrophin deficiency (serum $\mathrm{LH}$ or $\mathrm{FSH}<1.5 \mathrm{IU} / \mathrm{L}$ ) in half of patients (18/36), thyrotropin deficiency in

Table 3 Headache in patients presenting with pituitary apoplexy.

\begin{tabular}{|c|c|}
\hline Characteristics of headache & $\begin{array}{c}\text { Number/total in whom data } \\
\text { available }\end{array}$ \\
\hline \multicolumn{2}{|l|}{ Onset } \\
\hline Sudden & $17 / 23$ \\
\hline Insidious & $6 / 23$ \\
\hline \multicolumn{2}{|l|}{ Duration } \\
\hline Less than a day & $4 / 19$ \\
\hline 1 day to a week & $12 / 19$ \\
\hline More than a week & $3 / 19$ \\
\hline \multicolumn{2}{|l|}{ Lateralisation } \\
\hline Unilateral & $11 / 17$ \\
\hline Bilateral & $6 / 17$ \\
\hline \multicolumn{2}{|l|}{ Distribution } \\
\hline Frontal & $6 / 17$ \\
\hline Temporal & $5 / 17$ \\
\hline Occipital & $1 / 17$ \\
\hline Occipito-frontal & $2 / 17$ \\
\hline Temporo-occipital & $1 / 17$ \\
\hline Fronto-temporal & $1 / 17$ \\
\hline Apical & $1 / 17$ \\
\hline \multicolumn{2}{|l|}{ Association* } \\
\hline Neck stiffness & $4 / 17$ \\
\hline Photophobia & $7 / 18$ \\
\hline Phonophobia & $1 / 5$ \\
\hline Temperature $>38^{\circ} \mathrm{C}$ & $3 / 8$ \\
\hline
\end{tabular}

*Four patients reported positional changes (remainder unknown): three patients reported improvement in headache on sitting up and one reported worsened headache on coughing.
$15 / 43$ and low serum prolactin $(<100 \mathrm{U} / \mathrm{L})$ in $17 / 44$ (Table 4). Hyponatraemia (serum sodium $<135 \mathrm{mmol} / \mathrm{L}$ ) was present in 15 of 41 patients. No patient $(0 / 4)$ with a presenting cortisol $>400 \mathrm{nmol} / \mathrm{L}$ had hyponatraemia, whereas hyponatraemia was present in $5 / 10$ of those with a serum cortisol $100-400 \mathrm{nmol} / \mathrm{L}$, and $5 / 11$ of those with serum cortisol $<100 \mathrm{nmol} / \mathrm{L}$. Conversely, 5/9 of patients with hyponatraemia had a serum cortisol $<100 \mathrm{nmol} / \mathrm{L}$, compared with $6 / 20$ of those without hyponatraemia.

\section{Imaging modalities and findings}

CT was the most common imaging modality used in the initial assessment of patients presenting with pituitary apoplexy (27/45) (Table 5). On MRI pituitary, features consistent with haemorrhage predominating was more commonly present (31/43) than infarction (12/43) (Table 5).

\section{Type and size of adenoma}

The vast majority (45/46) of patients presenting with pituitary apoplexy had macroadenoma, with a median maximal diameter of $22.5 \mathrm{~mm}$ (IQR 15.3-29.0), whilst one patient had a normal pituitary gland (Table 5). NFPA was the commonest associated pituitary tumour (47/52), followed by prolactinoma (5/52) (Table 1). Ki67 and p53 were difficult to assess in the majority of histopathological samples due to haemorrhage/necrosis; however, in six samples where it was possible to assess these markers, Ki67 at 4-5\% and p53 were clearly present in one patient, but absent or present at very low levels in the remaining five patients.

\section{Conservative vs surgical management}

In our cohort of patients with pituitary apoplexy, 33 of 52 patients were treated conservatively and 19 had surgical decompression. In those patients with complete data available, 2 of 15 patients who had surgical decompression had decreased visual acuity, 8/14 had a visual field defect and 7/15 had ocular palsies (Table 6). Two patients had pituitary surgery because their repeat imaging showed increased tumour size after the apoplectic event. A nonsignificantly higher proportion of patients with impaired visual acuity $(2 / 15$ vs $1 / 20)$ or visual field defect $(8 / 14$ vs $5 / 21$ ) were treated surgically than conservatively. The prevalence of ocular palsies was similar in both groups. No presenting biochemical markers were significantly different between those managed conservatively and those managed surgically (Table 6). In both surgically

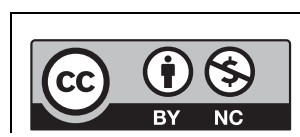

This work is licensed under a Creative Commons Attribution-NonCommercial 4.0 International License. 
Table 4 Biochemical abnormalities in patients presenting with pituitary apoplexy.

Biochemical parameter

Sodium level $(A=41, N A=11)$ (reference range $135-145 \mathrm{nmol} / \mathrm{L}$ )

Pre-treatment cortisol $(A=31, N A=21)(n m o l / L)$

Prolactin level $(A=44, N A=8)(150-450 \mathrm{mlU} / \mathrm{L})$

LH level $(A=36, N A=16)(I U / L)$

FSH level $(A=35, N A=17)(I U / L)$

TSH level $(A=43, N A=9)$ (reference range $0.3-4.1 \mathrm{mlU} / \mathrm{L}$ )

IGF1 level $(A=35, N A=17)(\mathrm{nmol} / \mathrm{L})$

\begin{tabular}{cc} 
Range & Number/total in whom data available \\
\hline $136-145$ & $26 / 41$ \\
$130-135$ & $6 / 41$ \\
$120-129$ & $7 / 41$ \\
$110-119$ & $2 / 41$ \\
$401-677$ & $4 / 31$ \\
$100-400$ & $15 / 31$ \\
$<100$ & $12 / 31$ \\
$\leq 100$ & $17 / 44$ \\
$101-500$ & $12 / 44$ \\
$>500$ & $15 / 44$ \\
$<1.5$ & $18 / 36$ \\
$\geq 1.5$ & $18 / 36$ \\
$<1.5$ & $10 / 35$ \\
$\geq 1.5$ & $25 / 35$ \\
$<0.3$ & $15 / 43$ \\
$0.3-4.1$ & $26 / 43$ \\
$>4.1$ & $2 / 43$ \\
$<14$ & $4 / 35$ \\
$14-49$ & $31 / 35$ \\
$>49$ & 0 \\
&
\end{tabular}

A, available data; FSH, follicle stimulating hormone; IGF1, insulin like growth factor 1; LH, luteinising hormone; NA, data not available; TSH, thyroidstimulating hormone. treated (14/14) and conservatively (5/5) managed groups, all patients experienced some improvement in neuroophthalmic deficits, which they described as improvement in blurred vision, visual fields, diplopia or ptosis. None of the patients with visual deficits who were managed conservatively $(0 / 5)$ and 5 of 11 patients managed surgically had complete resolution of their visual deficit.

None of the patients in this series recovered all pituitary endocrine deficits. All patients were discharged on hydrocortisone replacement. Most patients required corticosteroid replacement in the longer term following discharge (17/18 of those conservatively-treated, 10/12 of those surgically managed). One surgically treated $(1 / 18)$ and one conservatively managed (1/12) patient developed diabetes insipidus requiring desmopressin therapy on discharge from hospital. In both surgically treated and conservatively managed patients, half required levothyroxine on discharge from hospital. Two surgically treated (2/7) and two conservatively managed (2/11) male patients received testosterone replacement on discharge were prescribed HRT (1/5) on discharge from hospital. from hospital (Table 6). Two surgically treated women

Table 5 Imaging characteristics of pituitary apoplexy.

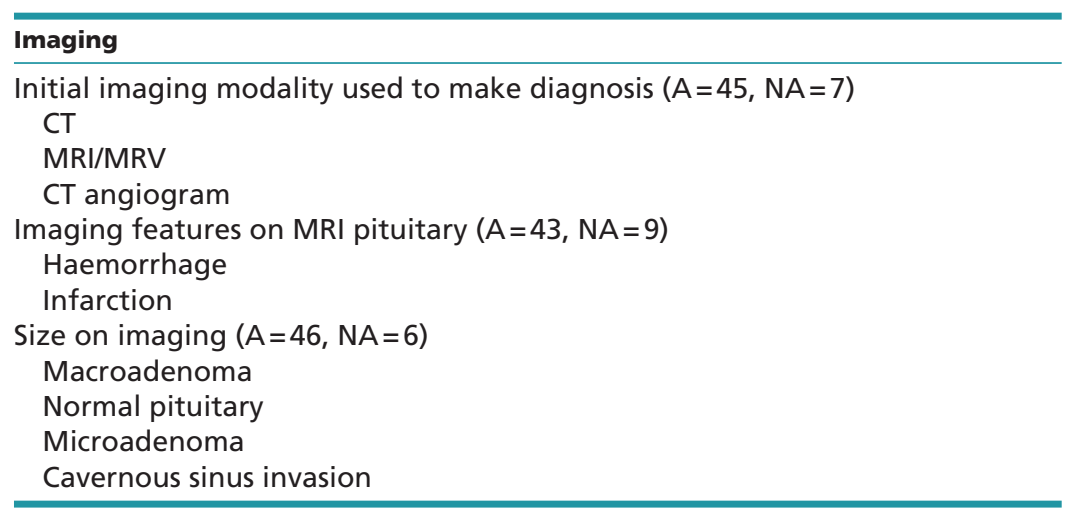

\begin{tabular}{c} 
Number/total in whom data available \\
\hline $27 / 45$ \\
$15 / 45$ \\
$3 / 45$ \\
\\
$31 / 43$ \\
$12 / 43$ \\
$45 / 46$ \\
$1 / 46$ \\
0 \\
$9 / 38$
\end{tabular}

Initial imaging modality used to reach diagnosis of apoplexy is presented. The majority of patients $(n=36)$ subsequently had dedicated pituitary MRI imaging. Haemorrhage may complicate infarction and thus many patients will have a mixture of both features. The proportion of patients with features consistent with predominantly haemorrhage and the proportion of patients with features suggestive of infarction without overt haemorrhage is presented.

$\mathrm{CT}$, computed tomography; MRI, magnetic resonance imaging; MRV, magnetic resonance venogram.
(C) 2018 The authors Published by Bioscientifica Ltd

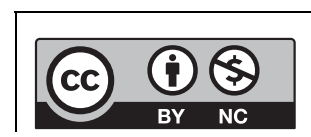

This work is licensed under a Creative Commons Attribution-NonCommercial 4.0 International License. 
Table 6 Outcome of patients following conservative or surgical management.

\begin{tabular}{|c|c|c|c|c|c|}
\hline $\begin{array}{l}\text { Characteristics and outcome of patients after } \\
\text { conservative or surgical management }\end{array}$ & Conservative & Surgery & Odds ratio & P-Value & Confidence interval \\
\hline$N$ number (male/female) & $14 / 19$ & $11 / 8$ & & & \\
\hline \multicolumn{6}{|l|}{ At presentation } \\
\hline Proportion with decreased visual acuity & $1 / 20$ & $2 / 15$ & 3.56 & 0.08 & $0.86-14.63$ \\
\hline Proportion with visual field defect & $5 / 21$ & $8 / 14$ & 2.77 & 0.43 & $0.23-33.88$ \\
\hline Proportion with ocular palsies & $10 / 20$ & $7 / 15$ & 0.88 & 0.85 & $0.23-3.34$ \\
\hline Proportion with hyponatraemia (<135IU/L) & $8 / 27$ & $4 / 14$ & 0.95 & 0.94 & $0.23-3.94$ \\
\hline Proportion with low cortisol $(<100 \mathrm{nmol} / \mathrm{L})$ & $10 / 22$ & $2 / 9$ & 0.34 & 0.24 & $0.06-2.03$ \\
\hline Proportion with low prolactin (<100 mIU/L) & $10 / 30$ & $7 / 14$ & 2.00 & 0.29 & $0.55-7.30$ \\
\hline Proportion with high prolactin ( $>500 \mathrm{mlU} / \mathrm{L})$ & $11 / 30$ & $4 / 14$ & 0.69 & 0.60 & $0.17-2.74$ \\
\hline \multicolumn{6}{|l|}{ Outcome } \\
\hline $\begin{array}{l}\text { Proportion with visual disturbance with at } \\
\text { least partial resolution of symptoms }\end{array}$ & $5 / 5$ & $14 / 14$ & - & - & - \\
\hline $\begin{array}{l}\text { Proportion with visual disturbance with full } \\
\text { resolution of visual symptoms }\end{array}$ & $0 / 5$ & $5 / 11$ & & & \\
\hline $\begin{array}{l}\text { Proportion with pituitary dysfunction with } \\
\text { full resolution of endocrine function }\end{array}$ & $0 / 12$ & $0 / 13$ & - & - & - \\
\hline \multicolumn{6}{|c|}{ Medications on discharge from hospital following admission for apoplexy } \\
\hline Glucocorticoid replacement & $18 / 18$ & $12 / 12$ & - & - & - \\
\hline Levothyroxine & $9 / 18$ & $6 / 12$ & - & - & - \\
\hline Dopamine agonist & $1 / 18$ & $0 / 12$ & - & - & - \\
\hline Desmopressin & $1 / 18$ & $1 / 12$ & - & - & - \\
\hline Testosterone* & $2 / 11$ & $2 / 7$ & - & - & - \\
\hline $\mathrm{HRT}^{\dagger}$ & $0 / 7$ & $2 / 5$ & & & \\
\hline
\end{tabular}

Partial resolution as self-reported by patients during follow up. Full resolution denotes no residual visual defect. Glucocorticoid treatment was with either hydrocortisone or prednisolone. No significant differences were observed in categorical variables when compared by unadjusted logistic regression.

*Only number of men were used as denominator for those requiring testosterone on discharge from hospital; ${ }^{\dagger}$ only number of women were used as denominator for those requiring HRT on discharge from hospital.

HRT, hormone replacement therapy.

\section{Discussion}

We present clinical and biochemical characteristics of a relatively large series $(n=52)$ of patients presenting with pituitary apoplexy to a tertiary neurosurgical/endocrine centre. Patients incidentally noted to have haemorrhagic or necrotic areas on pathological or radiological examination without clinical signs or symptoms were not included in this series $(1,3,11,17)$. Three patients presented with acute visual disturbances without headache, but the acute presentation and pituitary imaging were consistent with apoplexy.

The median age of the patients presenting with pituitary apoplexy in our cohort was 46.7 (IQR 31.5-57.0) years, which is consistent with the mean ages (38-52 years) observed in other series $(11,12,13,14$, 15). Pituitary apoplexy is often reported to occur more frequently in men than in women; however, we observed equal gender distribution in our series $(6,11,14,15)$. All but one case of pituitary apoplexy in our series were in the context of a macroadenoma, especially non-functioning adenomas $(5,10,18,19)$. Pituitary apoplexy is more likely to occur in macroadenomas as these tumours can outstrip

$\begin{array}{lr}\text { https://ec.bioscientifica.com } & \text { ○ } 2018 \text { The authors } \\ \text { https://doi.org/10.1530/EC-18-0255 } & \text { Published by Bioscientifica Ltd }\end{array}$

their blood supply/compress the surrounding venous plexus predisposing them to ischaemia/haemorrhage (15, 17, 20). Non-functioning adenomas exhibit symptoms later than functional tumours and thus may present at a later stage at larger sizes $(7,11,17)$. Cinar et al. 2013 have suggested an increased incidence of cavernous sinus invasion in patients with pituitary apoplexy. In our series, the median (IQR) of maximal diameter was 22.5 $(15.3-29.0 \mathrm{~mm})$ and $9 / 38$ patients had cavernous sinus invasion, which is consistent with their findings (21).

Potential predisposing factors to pituitary apoplexy were noted in $28 / 52$, which is consistent with figures reported in other series $(8,10,12)$. Frequently described predisposing factors include dopamine agonist use, anticoagulant use, head trauma or recent surgery $(4,12$, $14,20,22,23)$. Anticoagulant medications may favour a bleeding diathesis in patients with pituitary adenomas which harbour a rich vascular network $(2,24)$. In our study, we observed apoplectic episodes in three patients receiving antiplatelet/anticoagulant therapy for suspected acute coronary syndromes. Similar cases have been reported in other retrospective series, but there remains insufficient evidence to propose a recommendation

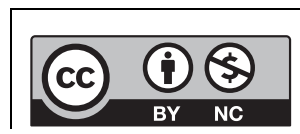

This work is licensed under a Creative Commons Attribution-NonCommercial 4.0 International License. 
contraindicating anticoagulation use in patients with known pituitary adenoma $(2,4,5,9)$.

Pregnancy increases the metabolic demand of the pituitary gland and is associated with pituitary gland hyperplasia, potentially due to increased oestradiol levels. It is possible that rapid expansion of a pituitary adenoma in combination with higher levels of oestradiol/procoagulant tendency during pregnancy could predispose to apoplexy $(5,25)$. Pituitary apoplexy was observed in the peripartum period in more than a quarter of women $(7 / 27)$ in our series. Three women presented after delivery (one caesarean-section and two had normal vaginal delivery), whilst four women presented in the third trimester, of whom two were pre-eclamptic.

The role and relevance of dopamine agonists in pituitary apoplexy remains unclear. Many reports have described spontaneous pituitary haemorrhage in prolactinomas $(4,5,7,8,9,26)$. However, the rate of pituitary apoplexy in macroprolactinomas treated with dopamine agonists is reported to be $1-6 \%$, which was similar to those in untreated macroprolactinomas (27, 28 ), and some authors have even suggested a protective role of dopamine agonists against pituitary apoplexy in macroprolactinoma (4).

Chronic hypertension was present in 17/52 patients and diabetes mellitus was present in 4/52 of patients. Though hypertension and diabetes mellitus are speculated to predispose to pituitary apoplexy by causing degenerative changes in pituitary gland microvasculature, a recent retrospective study by Moller-Goede et al. showed no difference in their frequencies in patients with pituitary apoplexy compared to matched controls with pituitary adenoma $(4,5,10)$.

Severe headache is the most common presenting symptom of pituitary apoplexy, being recorded in almost all patients with pituitary apoplexy. In the current study, headache was most frequently reported as sudden in onset, severe and lateralising to the frontal or temporal region. Symptoms of meningeal irritation may be present due to extravasation of blood into the subarachnoid space can cause fever, photophobia, neck stiffness or even collapse. Photophobia was present in $7 / 18$; and symptoms of meningism co-localised i.e. patients with phonophobia, collapse or neck stiffness also reported photophobia. One patient in our cohort presented with singultus (persistent hiccups), but did not also report photophobia. Bagir et al. reported a similar case of pituitary apoplexy in a 32-yearold man with pituitary macroadenoma who presented with persistent hiccups and severe headache (29). The reflex arc responsible for hiccup involves the peripheral, phrenic, vagal and central midbrain and the process of hiccup has been attributed to irritation of central processing in the midbrain following pituitary apoplexy (29). Early diagnosis of pituitary apoplexy can be challenging with substantial clinical overlap with other acute neurosurgical emergencies such as subarachnoid haemorrhage and thus a high index of suspicion is required. Indeed, although imaging slices on CT scan may not necessarily capture the pituitary gland, 27/45 in our series were initially diagnosed on CT examination before a subsequent dedicated pituitary MRI scan was carried out.

Preceding symptoms of endocrine dysfunction were present in 16/45. Hyponatraemia was noted in 15/41, due to either syndrome of inappropriate antidiuretic hormone secretion or glucocorticoid insufficiency (30). Whilst pituitary apoplexy is regarded as a stress response, the highest serum cortisol at presentation in our cohort was $677 \mathrm{nmol} / \mathrm{L}$. In our cohort, 5/9 patients with hyponatraemia had a pre-treatment serum cortisol level of $<100 \mathrm{nmol} / \mathrm{L}$ compared with $6 / 20$ of those with serum sodium levels within the reference range. However, presenting serum sodium level was not a reliable predictor of glucocorticoid insufficiency $(4,8,9,11,14)$.

The acute management of pituitary apoplexy is predominantly supportive including fluid resuscitation and correction of hormonal deficiencies $(1,31)$. Relieving extrinsic compression of the optic pathways through early surgical intervention remains a subject of conjecture, as surgery carries a risk of postoperative CSF rhinorrhoea and posterior pituitary damage $(1,15,31)$. Earlier literature argued that surgical decompression could improve pituitary function, which is often impaired $(18,32)$. In our study, we observed minimal endocrine recovery in either surgically, or conservatively managed patients. This observation is not surprising given that hypopituitarism is more common in macroadenomas even when not also complicated by pituitary apoplexy. Recent publications have resonated with this observation suggesting that endocrine outcome is poor regardless of management approach and that severity of endocrine deficiency should not be used to influence treatment approaches $(7,8,26)$.

In our series, neuro-ophthalmic improvement was present in both conservatively and surgically managed patients, suggesting that acute decisions undertaken through the pituitary multidisciplinary team regarding surgical management at our centre are likely to be appropriate. Whilst the majority of patients had some recovery in visual disturbance, none $(0 / 5)$ in the conservatively managed group and 5/11 of the surgically managed group had full recovery of neuro-ophthalmic

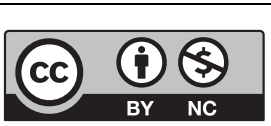

This work is licensed under a Creative Commons Attribution-NonCommercial 4.0 International License. 
deficits, supporting the use of surgery where indicated in the opinion of the multidisciplinary team. Retrospective studies that compare neuro-ophthalmic outcomes following conservative or surgical management have been equally inconclusive about the superiority of either treatment approach $(8,26,33,34)$. All authors report a pre-selection bias in which patients with more severe symptoms are also more likely to be offered surgical treatment, as is also probable in our series $(1,31)$.

It is possible that our patient numbers are too small for some comparisons due to the rarity of this presentation. As a tertiary referral centre, some patients were referred from local hospitals, limiting full documentation of some details of their presentation/follow-up. For scientific integrity, we treated lack of confirmation of presence/ absence of symptoms as 'missing data' unless symptoms/ signs were specifically documented to have been present or absent. Thus, in some instances, a lack of inclusion of a sign or symptom may indicate a failure of clear documentation rather than definitive presence/absence of this clinical feature. Despite these limitations, our study has yielded interesting data on the presentation and course of patients with a rare presentation of pituitary apoplexy in a relatively large cohort of patients presenting to a tertiary referral centre.

In summary, our data confirm the demographics, presenting clinical and biochemical features, predisposing factors and tumour types observed in other large series of patients with pituitary apoplexy. We provide further detail regarding the type of headache experienced by patients with pituitary apoplexy, being more commonly unilateral and fronto-temporal. More than half of patients had a potential predisposing factor to increase the risk of apoplexy and over a quarter of women in our series with pituitary apoplexy did so during the peri-partum period. Whilst most patients present with a sudden-onset headache, a significant proportion of patients reported a more insidious onset. Indeed, the headache was present for at least one day in the majority of patients where this is recorded, and more than one-third of patients had preceding symptoms consistent with endocrine dysfunction prior to presentation. However, a pre-existing diagnosis of pituitary disease was not previously apparent in most cases; thus, a high index of suspicion is required to prevent delay in diagnosis and management. We support the need for a prospective randomised clinical trial to try to better answer the question as to when surgery or conservative management is most appropriate. As apoplexy is such a rare condition, this will only be possible if several pituitary centres of excellence participate in such a study.

\section{Declaration of interest}

The authors declare that there is no conflict of interest that could be perceived as prejudicing the impartiality of the research reported.

\section{Funding}

This work did not receive any specific grant from any funding agency in the public, commercial or not-for-profit sectors.

Ethics and consent

Ethics and consent were not required for this study. Audit approval (AMC_012).

\section{References}

1 Rajasekaran S, Vanderpump M, Baldeweg S, Drake W, Reddy N, Lanyon M, Markey A, Plant G, Powell M, Sinha S, et al. UK guidelines for the management of pituitary apoplexy Pituitary Apoplexy Guidelines Development Group: May 2010. Clinical Endocrinology 201174 9-20. (https://doi.org/10.1111/j.1365-2265.2010.03913.x)

2 Briet C, Salenave S \& Chanson P. Pituitary apoplexy. Endocrinology and Metabolism Clinics of North America 201544 200-209. (https:// doi.org/10.1016/j.ecl.2014.10.016)

3 Brougham M, Price Heusner A \& Raymond Adams ND. Acute degenerative changes in adenomas of the pituitary body with special reference to pituitary apoplexy. Nuerosurgery 19507 421-439. (https://doi.org/10.3171/jns.1950.7.5.0421)

4 Möller-Goede DL, Brändle M, Landau K, Bernays RL \& Schmid C. Pituitary apoplexy: re-evaluation of risk factors for bleeding into pituitary adenomas and impact on outcome. European Journal of Endocrinology 2011164 37-43. (https://doi.org/10.1530/EJE-10-0651)

5 Biousse V, Newman NJ \& Oyesiku NM. Precipitating factors in pituitary apoplexy. Journal of Neurology, Neurosurgery, and Psychiatry 200171 542-545. (https://doi.org/10.1136/jnnp.71.4.542)

6 Randeva HS, Schoebel J, Byrne J, Esiri M, Adams CB \& Wass J. Classical pituitary apoplexy: clinical features, management and outcome. Clinical Endocrinology 199951 181-188. (https://doi. org/10.1046/j.1365-2265.1999.00754.x)

7 Gruber A, Clayton J, Kumar S, Robertson I, Howlett TA \& Mansell P. Pituitary apoplexy: retrospective review of 30 patients - is surgical intervention always necessary? British Journal of Neurosurgery $2006 \mathbf{2 0}$ 379-385. (https://doi.org/10.1080/02688690601046678)

8 Leyer C, Castinetti F, Morange I, Gueydan M, Oliver C, ConteDevolx B, Dufour H \& Brue T. A conservative management is preferable in milder forms of pituitary tumor apoplexy. Journal of Endocrinological Investigation 201134 502-509. (https://doi. org/10.3275/7241)

9 Sarwar KN, Huda MSB, Van De Velde V, Hopkins L, Luck S, Preston R, McGowan BM, Carroll PV \& Powrie JK. The prevalence and natural history of pituitary hemorrhage in prolactinoma. Journal of Clinical Endocrinology and Metabolism 201398 2362-2367. (https://doi. org/10.1210/jc.2013-1249)

10 Semple PL, Jane JA \& Laws ER. Clinical relevance of precipitating factors in pituitary apoplexy. Neurosurgery 200761 956-961. (https:// doi.org/10.1227/01.neu.0000303191.57178.2a)

11 Dubuisson AS, Beckers A \& Stevenaert A. Classical pituitary tumour apoplexy: clinical features, management and outcomes in a series of 24 patients. Clinical Neurology and Neurosurgery 2007109 63-70. (https://doi.org/10.1016/j.clineuro.2006.01.006)

12 Wakai S, Fukushima T, Teramoto A \& Sano K. Pituitary apoplexy: its incidence and clinical significance. Journal of Neurological Surgery 198155 187-193. (https://doi.org/10.3171/jns.1981.55.2.0187)

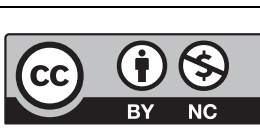


13 Bonicki W, Kasperlik-Załuska A, Koszewski W, Zgliczyński W \& Wisławski J. Pituitary apoplexy: endocrine, surgical and oncological emergency. Incidence, clinical course and treatment with reference to 799 cases of pituitary adenomas. Acta Neurochirurgica 1993120 118-122. (https://doi.org/10.1007/BF02112028)

14 Semple PL, Webb MK, De Villiers JC \& Laws ER. Pituitary apoplexy. Neurosurgery 200556 65-72. (https://doi.org/10.1227/01. NEU.0000144840.55247.38)

15 Rutkowski MJ, Kunwar S, Blevins L \& Aghi MK. Surgical intervention for pituitary apoplexy: an analysis of functional outcomes. Neurosurgery 2017129 417-424. (https://doi. org/10.3171/2017.2.JNS1784)

16 Bills DC, Meyer FB, Laws ER Jr, Davis DH, Ebersold MJ, Scheithauer BW, Ilstrup DM \& Abboud CF. A retrospective analysis of pituitary apoplexy. Neurosurgery 199333 602-609.

17 Semple PL, Jane JA, Lopes MBS \& Laws ER. Pituitary apoplexy: correlation between magnetic resonance imaging and histopathological results. Journal of Neurological Surgery $2008 \mathbf{1 0 8}$ 909-915. (https://doi.org/10.3171/JNS/2008/108/5/0909)

18 Randeva HS, Schoebel J, Byrne J, Esiri M, Adams CBT \& Wass JAH. Classical pituitary apoplexy: clinical features, management and outcome. Clinical Endocrinology 199951 181-188. (https://doi. org/10.1046/j.1365-2265.1999.00754.x)

19 Fernandez A, Karavitaki N \& Wass J. Prevalence of pituitary adenomas: a community-based, cross-sectional study in Banbury (Oxfordshire, UK). Clinical Endocrinology 201072 377-382. (https:// doi.org/10.1111/j.1365-2265.2009.03667.x)

20 Nawar RN, Abdel Mannan D, Selman WR \& Arafah BM. Analytic review: pituitary tumor apoplexy: a review. Journal of Intensive Care Medicine 200823 75-90. (https://doi. org/10.1177/0885066607312992)

21 Cinar N, Tekinel Y, Dagdelen S, Oruckaptan H, Soylemezoglu F \& Erbas T. Cavernous sinus invasion might be a risk factor for apoplexy. Pituitary 201316 483-489. (https://doi.org/10.1007/s11102-0120444-2)

22 Hidiroglu M, Kucuker A, Ucaroglu E, Kucuker Sa \& Sener E. Pituitary apoplexy after cardiac surgery. Annals of Thoracic Surgery 201089 1635-1637. (https://doi.org/10.1016/j.athoracsur.2009.09.038)

23 Masago A, Ueda Y, Kanai H, Nagai H \& Umemura S. Pituitary apoplexy after pituitary function test: a report of two cases and review of the literature. Surgical Neurology 199543 158-164; discussion 165. (https://doi.org/10.1016/0090-3019(95)80128-4)

24 Willamowicz AS \& Houlden RL. Pituitary apoplexy after anticoagulation for unstable angina. Endocrine Practice 19995 273-276. (https://doi.org/10.4158/EP.5.5.273)
25 Grand'Maison S, Weber F, Bedard M-J, Mahone M \& Godbout A. Pituitary apoplexy in pregnancy: a case series and literature review. Obstetric Medicine 20158 177-183. (https://doi.org/10.1177/17534 95X15598917)

26 Bujawansa S, Thondam SK, Steele C, Cuthbertson DJ, Gilkes CE, Noonan C, Bleaney CW, MacFarlane IA, Javadpour M \& Daousi C. Presentation, management and outcomes in acute pituitary apoplexy: a large single-centre experience from the United Kingdom. Clinical Endocrinology 201480 419-424. (https://doi.org/10.1111/ cen.12307)

27 Carija R \& Vucina D. Frequency of pituitary tumor apoplexy during treatment of prolactinomas with dopamine agonists: a systematic review. CNS and Neurological Disorders: Drug Targets 201211 1012-1014. (https://doi.org/10.2174/1871527311211080011)

28 Rastogi A, Bhansali A, Dutta P, Singh P, Vijaivergiya R, Gupta V, Sachdeva N, Bhadada SK \& Walia R. A comparison between intensive and conventional cabergoline treatment of newly diagnosed patients with macroprolactinoma. Clinical Endocrinology 201379 409-415. (https://doi.org/10.1111/cen.12149)

29 Bagir GS, Civi S, Kardes O \& Kayaselcuk F. Stubborn hiccups as a sign of massive apoplexy in a naive acromegaly patient with pituitary macroadenoma. Endocrinology, Diabetes and Metabolism Case Reports 2017 17-0044. (https://doi.org/10.1530/EDM-17-0044)

30 Verbalis JG, Goldsmith SR, Greenberg A, Korzelius C, Schrier RW, Sterns RH \& Thompson CJ. Diagnosis, evaluation, and treatment of hyponatremia: expert panel recommendations. American Journal of Medicine 2013126 (10 Supplement 1) S1-S42. (https://doi. org/10.1016/j.amjmed.2013.07.006)

31 Baldeweg SE, Vanderpump M, Drake W, Reddy N, Markey A, Plant GT, Powell M, Sinha S, Wass J \& Society for Endocrinology Clinical Committee. SOCIETY FOR ENDOCRINOLOGY ENDOCRINE EMERGENCY GUIDANCE: Emergency management of pituitary apoplexy in adult patients. Endocrine Connections 20165 12-15. (https://doi.org/10.1530/EC-16-0057)

32 Arafah BM, Harrington JF, Madhoun ZT \& Selman WR. Improvement of pituitary-function after surgical decompression for pituitary-tumor apoplexy. Journal of Clinical Endocrinology and Metabolism $19907 \mathbf{1}$ 323-328. (https://doi.org/10.1210/jcem-71-2-323)

33 Tu M, Lu Q, Zhu P \& Zheng W. Surgical versus non-surgical treatment for pituitary apoplexy: a systematic review and metaanalysis. Journal of the Neurological Sciences $2016370258-262$. (https://doi.org/10.1016/j.jns.2016.09.047)

34 Giritharan S, Gnanalingham K \& Kearney T. Pituitary apoplexybespoke patient management allows good clinical outcome. Clinical Endocrinology 201685 415-422. (https://doi.org/10.1111/cen.13075)

Received in final form 16 August 2018

Accepted 22 August 2018

Accepted Preprint published online 23 August 2018

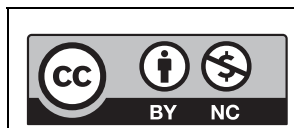

This work is licensed under a Creative Commons Attribution-NonCommercial 4.0 International License. 